\title{
EEG and serum prolactin studies in relation to transcutaneous stimulation of central motor pathways
}

\author{
SG BOYD, LVK DE SILVA* \\ From the Departments of Clinical Neurophysiology \& Clinical Biochemistry, The Hospital for Sick Children, \\ Great Ormond Street, London, UK.
}

SUMMARY Eight adult volunteers had EEG recordings and serial serum prolactin estimations performed both before and after a session of transcutaneous stimulation of the central motor pathways using the technique of Merton and Morton. No significant changes in either the EEG traces or in the serum prolactin values were detected.

The ability to study function in central motor pathways, using techniques of transcutaneous stimulation through the intact scalp, is an important recent development in clinical neurophysiology. In a conscious subject, a single large shock from a purpose-built device is applied to the scalp over the motor cortex with disc or pad electrodes. The resulting contraction in peripheral muscles can be recorded using conventional apparatus. ${ }^{1}$ Studies on normal adults ${ }^{2}{ }^{3}$ and on patients with multiple sclerosis ${ }^{4}$ have recently been published.

The technique appears to be safe, and no adverse effects have been reported from amongst the several hundred subjects who have been tested. In addition, some of the original investigators have themselves received hundreds of stimuli without ill-effect. However, there have been no studies to delineate possible transitory physiological effects of transcutaneous stimulation.

Electroencephalograms (EEGs) taken immediately after unilateral electro-convulsive therapy (ECT) show marked slowing $(1-4 \mathrm{~Hz}$ activity reaching

*Present Address: King Abdul Aziz Naval Base Hospital, Jubail, Saudi Arabia.

Address for reprint requests: Dr SG Boyd, Department of Clinical Neurophysiology, The Hospital for Sick Children, Great Ormond Street, London WCIN 3JH, UK.

Received 29 November 1985. Accepted 15 December 1985
$50-200 \mu \mathrm{V}$ ) on the side of stimulation which persists for at least half an hour. ${ }^{56} \mathrm{~A}$ ten to fifty-fold increase in prolactin secretion 15 minutes after ECT has also been documented. ${ }^{78}$ Generalised tonic/clonic and complex partial seizures have been shown to produce significant (two to three fold) rises in serum prolactin in both adults ${ }^{9-13}$ and in children ${ }^{14}$ and this finding is being used widely in clinical practice to discriminate between seizures and pseudo-seizures. The optimum time for estimating the prolactin level has been determined to be 15-20 minutes following the seizure. ${ }^{9-11} 13$

Before the technique of transcutaneous stimulation is adopted as a routine procedure, particularly in children, it was considered worthwhile to study EEG and serum prolactin responses to transcutaneous stimulation in a group of healthy adult volunteers.

\section{Methods}

Eight healthy adult volunteers aged 24 to 55 years were studied. There were two males and six females. All were members of staff of the department or were medical colleagues. None were receiving medication. All gave informed consent, and the protocol for the study was approved by the Standing Committee on Ethical Practice of the Hospital for Sick Children. The EEGs were recorded from silver/silver chloride electrodes using previously described techniques, ${ }^{15}$ and included overbreathing for three minutes and photic stimulation at a wide range of flash frequencies.

Immediately prior to the session of transcutaneous stimulation, the EEG headbox was disconnected from the appara- 
Table

\begin{tabular}{|c|c|c|c|c|}
\hline$\overline{\text { Subject (no) }}$ & Age (yr) & $\begin{array}{l}\text { No. of stimuli to } \\
\text { scalp }\end{array}$ & $\begin{array}{l}\text { Range of valu } \\
\text { pre-stimulus }\end{array}$ & $\begin{array}{c}\text { polactin (mU/l) } \\
\text { post-stimulus }\end{array}$ \\
\hline $\begin{array}{l}1 \\
2 \\
3 \\
4 \\
5 \\
6 \\
7 \\
8\end{array}$ & $\begin{array}{l}24 \\
26 \\
32 \\
34 \\
47 \\
49 \\
54 \\
55\end{array}$ & $\begin{array}{r}10 \\
4 \\
5 \\
3 \\
10 \\
13 \\
5 \\
5\end{array}$ & $\begin{array}{c}326-370 \\
160-219 \\
567-581 \\
77-84 \\
171-175 \\
688-689 \\
127-156 \\
65-82\end{array}$ & $\begin{array}{c}289-318 \\
138-196 \\
471-578 \\
77-84 \\
99-196 \\
410-536 \\
100-140 \\
53-71\end{array}$ \\
\hline
\end{tabular}

tus to ensure isolation from the earth lead of the EEG machine. Transcutaneous stimulation of the motor cortex was then performed using a Digitimer D180 stimulator in accordance with methods described previously. ${ }^{1}$ Stimulus intensity was increased until consistent supramaximal responses were recorded. The rate of stimulation was between 1 per $5 \mathrm{~s}$ and about 1 per $30 \mathrm{~s}$. The number of stimuli was kept in line with that usually employed in routine diagnostic sessions and no attempt was made to subject the volunteers to large numbers of stimuli. (table)

Within half a minute of completing the session of stimulation, the EEG was reconnected and recording was continued for a further 30 mins. Hyperventilation and photic stimulation were repeated.

A cannula was sited in a forearm vein at the time of electrode placement, and was kept patent throughout the procedure with heparin. Blood samples for baseline serum prolactin estimation were obtained both 30 minutes before and also immediately prior to transcutaneous motor tract stimulation. Following the series of stimuli, further samples were obtained at five minute intervals for a period of thirty minutes. The first $\mathrm{ml}$ of each sample was discarded to avoid contamination with heparin. Serum prolactin was measured by radioimmunoassay using ${ }^{125} I$ and Guildhay G/R/51-VABC antisera. A second antibody was used for separation. Between assay coefficient of variation was $8 \cdot 3$, $11 \cdot 2$ and $10.6 \%$ at prolactin concentrations of 242,599 and $1328 \mathrm{mU} / 1$ respectively.

\section{Results}

The EEGs were reported independently by two experienced electroencephalographers. No differences were detected between the pre- and post- stimulation records, either in the resting record or in relation to hyperventilation and photic stimulation.

The baseline serum prolactin concentration was 283 $\pm 225 \mathrm{mU} / 1$ (mean $\pm \mathrm{SD})$. Prolactin concentration after the stimulus remained at $233+/-170 \mathrm{mU} / 1$ (mean \pm SD), during the thirty minutes the subjects were observed. None showed an increase in prolactin concentration over the baseline value (table). There was no significant difference between the mean prolactin concentrations before and after the stimulus.

\section{Discussion}

No previous studies of the effects of transcutaneous stimulation on the EEG have been reported. Although it was not practicable to record the EEG at the moment of the transcutaneous stimulus, the fact that no sustained EEG alteration occurs, (when using the numbers of transcutaneous stimuli with the stimulus intensities normally employed in clinical studies) is in marked contrast to the EEG changes reported after unilateral ECT. This is not surprising when the relative amounts of energy delivered to the patients are considered in the two situations. Assuming that there is no resistance in the electrode wires or in the scalp, and that all the energy is delivered to the patient, the maximum output of the Digitimer D180 (using a nominal time constant of $50 \mu \mathrm{s}$ ) would be about 0.25 joules, compared with the estimated $25-50$ joules used in the ECT sessions recorded by Kriss et al. ${ }^{6}$

Many conditions of mild to moderate "stress" have been shown to increase the serum prolactin. These include drugs such as butyrophenones, methyldopa and chlorpromazine, as well as anaesthesia and surgery. ${ }^{16}$ It is thought that prolactin secretion in all these situations (including ECT and seizures) is related to suppression of dopamine secretion in the arcuate and periventricular nuclei of the medial basal hypothalamus. ${ }^{813}$ No such rise in serum prolactin has been demonstrated in the present study, and it seems that transcutaneous stimulation of the motor tracts does not alter this dopamine system (either directly as a consequence of stimulation, or indirectly as a "stress" effect) at least using conventional clinical diagnostic techniques. It would obviously have been difficult to carry out this study in normal children, but there is no reason to suppose that EEG effects or prolactin would be affected any differently in a paediatric population.

We thank Dr Ann Harden for much help and advice, and for helping to interpret the EEG records. We also thank Miss Karen Huckin for taking the EEG records, and the other members of the Clinical 
Neurophysiology Department for their cooperation in this study.

\section{References}

${ }^{1}$ Merton PA, Morton HB, Hill DK, Marsden CD. Scope of a technique for electrical stimulation of human brain, spinal cord and muscle. Lancet 1982;ii:597-600.

${ }^{2}$ Marsden CD, Merton PA, Morton HB. Percutaneous stimulation of spinal cord and brain; pyramidal tract conduction velocities in man. J Physiol (Lond) 1982; 328:6P.

${ }^{3}$ Rossini PM, Di Stefano E, Stanzione P. Nerve impulse propagation along central and peripheral fast conducting motor and sensory pathways in man. Electroencephalogr Clin Neurophysiol 1984;60:320-34.

${ }^{4}$ Cowan JMA, Dick JPR, Day BL, Rothwell JC, Thompson PD, Marsden CD. Abnormalities in central motor pathway conduction in multiple sclerosis. Lancet 1984;ii:304-7.

${ }^{5}$ d'Elia G, Perris C. Comparison of electroconvulsive therapy with unilateral and bilateral stimulation. I. Seizure and post-seizure electroencephalographic pattern. Acta Psychiatr Scand 1970;Suppl 215:9-29.

${ }^{6}$ Kriss A, Halliday AM, Halliday E, Pratt RTC. EEG immediately after unilateral ECT. Acta Psychiatr Scand 1978;58:231-44.

${ }^{7}$ Ohman R, Walinder J, Balldin J, Wallin L. Prolactin response to electroconvulsive therapy. Lancet 1976; ii:936-7.

${ }^{8}$ O'Dea JPK, Gould D, Hallberg M, Weiland RG. Prolactin changes during electroconvulsive therapy. Am J Psychiatry 1978;135:609-611.

${ }^{9}$ Trimble MR. Serum prolactin in epilepsy and hysteria. $\mathrm{Br}$ Med J 1978;ii:1682.

${ }^{10}$ Abbott RJ, Browning MCK, Davidson DLW. Serum prolactin and cortisol concentration after grand mal seizures. J Neurol Neurosurg Psychiatry 1980;43:163-7.

${ }^{11}$ Collins WJC, Lanigan O, Callaghan N. Plasma prolactin concentrations following epileptic and pseudoseizures. J Neurol Neurosurg Psychiatry 1983;46:505-8.

${ }^{12}$ Laxer KD, Mullooly JP, Howell B. Prolactin changes after seizures classified by EEG monitoring. Neurology 1985;35:31-5.

${ }^{13}$ Dana-Haeri J, Trimble MR, Oxley J. Prolactin and gonadotrophin changes following generalised and partial seizures. J Neurol Neurosurg Psychiatry 1983;46:331-5.

${ }^{14}$ Bye AME, Nunn KP, Wilson J. Prolactin and seizure activity. Arch Dis Child 1985;60:848-51.

15 Pampiglione G. Some anatomical considerations upon electrode placement in routine EEG. Proc Electrophysiol Technol Assoc 1956;7:1-11.

${ }^{16}$ Noel GL, Suh HK, Stone JG, Franz AG. Human prolactin and growth hormone release during surgery and other conditions of stress. J Clin Endocrinol Metab 1972;35:840-51. 